First Peoples Child \& Family Review

An Interdisciplinary Journal Honouring the Voices, Perspectives, and Knowledges of

First Peoples through Research, Critical Analyses, Stories, Standpoints and Media

Reviews

\title{
Calgary's Family and Community Support Services' Social Sustainability Framework and Urban Aboriginal Peoples
}

\section{Shane R. Gauthier, Sharon Goulet and Katie Black}

Volume 6, Number 2, 2011

URI: https://id.erudit.org/iderudit/1068874ar

DOI: https://doi.org/10.7202/1068874ar

\section{See table of contents}

\section{Publisher(s)}

First Nations Child and Family Caring Society of Canada

\section{ISSN}

1708-489X (print)

2293-6610 (digital)

Explore this journal

Cite this article

Gauthier, S., Goulet, S. \& Black, K. (2011). Calgary's Family and Community Support Services' Social Sustainability Framework and Urban Aboriginal Peoples. First Peoples Child \& Family Review, 6(2), 20-34.

https://doi.org/10.7202/1068874ar

\section{Article abstract}

Family \& Community Support Services (FCSS) in Calgary is a joint municipal and provincial funding program. The program is designed to develop, support, and fund preventive social services. FCSS Calgary has a number of benefits and truly makes a difference in the community. At-risk youth and vulnerable senior citizens have avenues for positive community involvement, family violence victims are safer, newcomers are welcomed and can feel at home in Calgary, citizens have access to information about the community and crisis services, and urban Aboriginal people are able to develop leadership skills within the community. FCSS programs and agencies align with at least one of the funding priorities (Strengthening Neighbourhoods and Increasing Social Inclusion, outlined in the Social Sustainability Framework). Increasing Social Inclusion concentrates on five populations: families, children and youth, seniors, immigrants, and Aboriginal people (City of Calgary, Social Sustainability, 2010). The new Social Sustainability Framework helps the community in a number of ways. It guides funding decisions by providing FCSS Calgary with clear and consistent principles. By aligning funded programs with identified objectives and outcomes, it helps FCSS account for and communicate its impact on the community. There is an abundance of statistics that support the need for culturally appropriate programs for urban Aboriginal peoples. Research demonstrates urgency for these programs and the current social landscape of urban Aboriginal children, youth, and families. For example, between 1996 and 2006, the Aboriginal population across Canada grew by 45\% to reach close to 1.2 million persons, representing $3.8 \%$ of the Canadian population. (Statistics Canada, 2008, Canadian Demographics at a Glance, p. 34).Two examples of urban Aboriginal programs from Metis Calgary Family Services (MCFS) is presented within FCSS's Sustainability Framework; Native Network, and Little Dancing Buffalo.
This document is protected by copyright law. Use of the services of Erudit (including reproduction) is subject to its terms and conditions, which can be viewed online.

https://apropos.erudit.org/en/users/policy-on-use/ 


\title{
First Peoples Child \& Family Review
}

An Interdisciplinary Journal Honoring the Voices, Perspectives and Knowledges of First Peoples through Research, Critical Analyses, Stories, Standpoints and Media Reviews

\section{Calgary's Family and Community Support Services' Social Sustainability Framework and Urban Aboriginal Peoples}

\author{
Shane R. Gauthier ${ }^{a}$, Sharon Goulet ${ }^{\mathrm{b}}$ and Katie Black ${ }^{\mathrm{c}}$
}

a Consultation Manager, Aboriginal Relations, Government of Alberta, Edmonton, AB, Canada

b Sharon Goulet is a Red River Métis and member of the Métis Nation of Alberta. Sharon has lived in Calgary for 25 years, and has worked at the City of Calgary in Aboriginal Services for the past 18 years. As an Aboriginal Issue Strategist, Sharon's work involved social planning, community development, research, and advocacy on issues that concern the Aboriginal urban community. In 2007, Sharon took on the role of Social Planner with the City of Calgary's FCSS program and is responsible for funding, social planning and capacity development initiatives, as identified by Aboriginal agencies.

c Manager, City of Calgary. Katie is responsible for the development and implementation of the Social Sustainability Framework across 80 partner agencies including those that deliver services from an Aboriginal worldview. A social worker for the past 25 years, Katie is not Aboriginal but seeks to practice cultural humility and to learn from wise people around her. She is mother to teens Claudia and Adrian, and spouse to pianist/composer Gordon Rumson.

\section{Family \& Community Support Services Calgary}

Family \& Community Support Services (FCSS) in Calgary is a joint municipal and provincial funding program. The Family \& Community Support Services Act and Regulation governs the program and was enacted in 1981, replacing the Preventative Social Services Act (1966). The program is designed to develop, support, and fund

Questions or correspondence concerning this article may be addressed to:

Shane Gauthier, M.Ed

Consultation Manager, $\mathrm{Ph}: 780.644 .4653$

Consultation and Land Claims

Aboriginal Relations, Government of Alberta

19th, Floor, Commerce Place

10155-102 Street

Edmonton, Alberta T5J 4L6

Email: Shane.Gauthier@gov.ab.ca

\begin{abstract}
Family \& Community Support Services (FCSS) in Calgary is a joint municipal and provincial funding program. The program is designed to develop, support, and fund preventive social services. FCSS Calgary has a number of benefits and truly makes a difference in the community. At-risk youth and vulnerable senior citizens have avenues for positive community involvement, family violence victims are safer, newcomers are welcomed and can feel at home in Calgary, citizens have access to information about the community and crisis services, and urban Aboriginal people are able to develop leadership skills within the community. FCSS programs and agencies align with at least one of the funding priorities (Strengthening Neighbourhoods and Increasing Social Inclusion, outlined in the Social Sustainability Framework). Increasing Social Inclusion concentrates on five populations: families, children and youth, seniors, immigrants, and Aboriginal people (City of Calgary, Social Sustainability, 2010).

The new Social Sustainability Framework helps the community in a number of ways. It guides funding decisions by providing FCSS Calgary with clear and consistent principles. By aligning funded programs with identified objectives and outcomes, it helps FCSS account for and communicate its impact on the community. There is an abundance of statistics that support the need for culturally appropriate programs for urban Aboriginal peoples. Research demonstrates urgency for these programs and the current social landscape of urban Aboriginal children, youth, and families. For example, between 1996 and 2006, the Aboriginal population across Canada grew by $45 \%$ to reach close to 1.2 million persons, representing $3.8 \%$ of the Canadian population. (Statistics Canada, 2008, Canadian Demographics at a Glance, p. 34).

Two examples of urban Aboriginal programs from Metis Calgary Family Services (MCFS) is presented within FCSS's Sustainability Framework; Native Network, and Little Dancing Buffalo.

Key words: At risk youth, vulnerable senior citizens, urban Aboriginal people, Calgary, social inclusion, Social Sustainability Framework
\end{abstract}

preventive social services. Generally, the program concentrates on prevention, voluntarism, an 8020 cost sharing partnership between the Province and municipal partners, and enhanced local 
autonomy. However, FCSS Calgary has decided to contribute $25 \%$ of the cost to the program, instead of the minimum $20 \%$. Calgary has had a partnership with the Province for 44 years, since the launch of the PSS Act in 1966 ("FCSS Fact Sheet," 2010). The purpose of this paper is to introduce FCSS and its new social sustainability framework while providing examples of how urban Aboriginal programs like Little Dancing Buffalo and Native Network use its principles.

The Province's budget for FCSS in 2010/2011 is $\$ 75.2 \mathrm{M}$ and the total amount of funding that is allocated to Calgary for 2010 is $\$ 21.9 \mathrm{M}$. Calgary has contributed $\$ 7.4 \mathrm{M}$ in 2010 ("FCSS Fact Sheet," 2010). The City of Calgary FCSS Division manages the FCSS funding program and works with the community and agencies. The FCSS Division's two primary functions are service planning and funding allocations. FCSS funds programs and services that are consistent with the FCSS Act; are consistent with City Council's funding priorities, which are strengthening neighbourhoods and increasing social inclusion; are collaborative and not duplicate existing programs; involve volunteers; utilize evidence-based best practice; state objectives in measurable terms; and demonstrate good administration and governance (City of Calgary, FCSS Overview, 2010).

All of the FCSS-funded programs and agencies are supported in order to ensure that their work reflects evidence-based practices in prevention. Furthermore, an investment of \$1 in preventative social services produces a social return on investment of \$6-\$13 in other costs ("FCSS Fact Sheet," 2010). These costs include addictions treatment, justice, and policing and such an investment also increases contributions to society and productivity in employment.

FCSS Calgary's vision statement is "Calgarians working together to create and sustain a viable, safe, and caring community" (City of Calgary, FCSS Overview, 2010). Their mission is to partner with municipal agencies, other city businesses, and other funders to fund preventative social services that enhance and support the lives of Calgarians. By funding community organizations to strengthen neighbourhoods and increase social inclusion, FCSS Calgary minimizes and prevents the impact of social problems.

FCSS Calgary has a number of benefits and truly makes a difference in the community. Atrisk youth and vulnerable senior citizens have avenues for positive community involvement, family violence victims are safer, newcomers are welcomed and can feel at home in Calgary, citizens have access to information about the community and crisis services, and urban Aboriginal people are able to develop leadership skills within the community. FCSS programs and agencies align with at least one of the funding priorities (Strengthening Neighbourhoods and Increasing Social Inclusion, outlined in the Social Sustainability Framework). Increasing Social Inclusion concentrates on five populations: families, children and youth, seniors, immigrants, and Aboriginal people (City of Calgary, Social Sustainability, 2010).

The following section will discuss FCSS's new social sustainability framework.

\section{The New Social Sustainability Framework}

The focus of this section is to outline the new social sustainability framework and describe how it helps the community. In September 2007, FCSS Calgary started a three phase process to develop a new funding framework. The goal was to develop a long-term, multi-year framework for community investment in order to ensure preventive and comprehensive impact in the community and sustainability for FCSS. In 2008, the new Social Sustainability Framework was approved. 2009 was a planning year for the implementation of the framework and funding priorities and the new funding priorities started to be applied in 2010. The Social Sustainability Framework is the blueprint for FCSS investment decisions, funding practices, and social planning. For all aspects of its business, the City of Calgary has also adopted a Triple Bottom Line policy that includes economic, social, and environmental characteristics. The Social Sustainability Framework aligns with this policy, but also 
focuses on social sustainability for FCSS (City of Calgary, Social Sustainability, 2010).

The Social Sustainability Framework was developed to help FCSS Calgary maximize the impact of its investments in the community. This new framework is required because of changing social conditions, increased demand for services, and the state of the non-profit sector. The framework creates the opportunity to make differences in the community by preventing the development of serious social problems, particularly concentrated poverty and social isolation (City of Calgary, Social Sustainability, 2010).

Under the Social Sustainability Framework, FCSS has identified two investment priorities for the next ten years. The first funding priority is to strengthen neighbourhoods. Within ten years, FCSS Calgary hopes to see a decrease in the spatial concentration of poverty in the community and increased community capacity and capital in focus neighbourhoods (City of Calgary, Social Sustainability, 2010).

The second funding priority is to increase social inclusion. Ideally, within ten years, vulnerable Calgarians who participate in FCSS-funded programs will experience increased social inclusion and the focus will turn to vulnerable populations that are at risk of social exclusion. Vulnerable populations include immigrants, Aboriginal people, families, children and youth, and seniors (City of Calgary, Social Sustainability, 2010).

FCSS has chosen these two priorities for a few reasons. First, because "[c]oncentrated poverty and social isolation are very serious problems with far-reaching consequences for individuals, families, communities, and the city as a whole" (Cooper and Bartlett, 2008, p. 4). These problems include neighbourhood decline, isolation, social disorder, crime, negative child/youth development, cultural and religious tensions, and lack of community participation, low capital, poor health, poverty, and social exclusion. Second, the two funding priorities were chosen because "both concentrated poverty and social isolation are on the rise in Calgary" (p. 4). Third, extensive spatially-concentrated poverty and isolation in Calgary can be prevented. Finally,
"FCSS is ideally positioned to make a difference" (p. 5). No other social service funder has the connections to influence change at a municipal level. Although FCSS will not completely prevent social isolation and concentrated poverty, it can make a difference by working with other stakeholders, committing to the long-term plan, informing public policy, and supporting researchbased prevention programs (p. 5).

The new Social Sustainability Framework helps the community in a number of ways. It guides funding decisions by providing FCSS Calgary with clear and consistent principles. By aligning funded programs with identified objectives and outcomes, it helps FCSS account for and communicate its impact on the community. To ensure that programs continue to improve people's lives, it incorporates recent advances in prevention science. It directs funding toward supporting partnerships, collaboration, coordination, and integration. Finally, it aligns with related Calgary planning and policy initiatives. These funding priorities will be reviewed every three years in order to monitor and evaluate the impact of this new funding framework. Although adjustments may be implemented as needed, it is anticipated that the funding priorities will remain the same until 2018 (City of Calgary, Social Sustainability, 2010).

Calgary urban Aboriginal peoples, members of the vulnerable population, are the focus of the next section.

\section{Calgary Urban Aboriginal Peoples}

As stated earlier, one of the vulnerable populations that the Social Sustainability Framework focuses on is Aboriginal peoples. This section demonstrates the importance of offering programs and initiatives that help this vulnerable population. Increasing social inclusion for Calgary urban Aboriginal families is important. This population includes "individuals and communities that have been affected by the multigenerational impacts of colonialism, such as the effects of residential schools. These effects may include systemic racism and 
discrimination, resulting in chronic low income, high mobility, loss of culture, and other negative social indicators. Aboriginal peoples include First Nations (status, non-status and Bill C-31 individuals), Métis, and Inuit people" (City of Calgary, Social Sustainability, 2010).

For public policy, the issue has to do with choices between programs and institutions that are concentrated in or spatially targeted toward particular neighbourhoods, and initiatives that have a wider urban focus. There are a number of advantages associated with spatially targeted initiatives. Neighbourhood institutions may be more responsive to local needs, and they can be more accessible. They can serve to anchor an identity for a particular community, contribute to empowerment of local residents who participate in these institutions, and help to create a feeling of collective belonging (Peters, 2004, p. 7). However, it is important to note that "Aboriginal poverty is a factor of everyday life for many Aboriginal people in urban areas. Many urban Aboriginal residents do not possess the financial resources to support institutional development" (Peters, 2005, p. 381).

There is an abundance of statistics that support the need for culturally appropriate programs for urban Aboriginal peoples. Research demonstrates urgency for these programs and the current social landscape of urban Aboriginal children, youth, and families. For example, between 1996 and 2006, the Aboriginal population across Canada grew by $45 \%$ to reach close to 1.2 million persons, representing 3.8\% of the Canadian population. (Statistics Canada, 2008, Canadian Demographics at a Glance, p. 34). Furthermore, in 1901 , only $5.1 \%$ of Aboriginal people lived in urban areas, and that percentage had increased to only $6.7 \%$ by 1951 (Kalbach, 1987, p. 102, cited in Peters, 2004, p. 2). More specifically, in Calgary, as of 2001 the Aboriginal identity population totalled 22,110, which translates to $2.3 \%$ of urban population with Aboriginal identity, which is a $57.1 \%$ increase from 1991 to 2001 (Peters, 2004, p. 4). These trends indicate that the Aboriginal population is growing at a faster rate than the rest of the Canadian population.
Furthermore, the urban Aboriginal population has grown much faster than the overall Aboriginal population: "Between 2001 and 2006, the population of people identifying as Aboriginal in Edmonton and Calgary increased by $25.2 \%$, compared to a $20.6 \%$ increase of the total Aboriginal population (Table 2). This trend will increase demand on municipalities for programs and services that address Aboriginal issues. To develop targeted programs and services, Aboriginal organizations will need to interact with municipal governments more frequently" (Aboriginal Relations, 2011, p. 4).

Many young First Nations children living offreserve are growing up in communities where Aboriginal people represent a small minority among a diversity of cultures. In many of these communities, it is likely more difficult to maintain ties to traditional Aboriginal cultures than in communities where Aboriginal people represent the majority of the population. Almost half (46\%) of young First Nations children living off-reserve had participated in or attended traditional Aboriginal activities. Children in rural areas were more likely to have taken part in these traditional and cultural activities than children living in urban areas (Statistics Canada, 2008, Canadian Social Trends, p. 67). Furthermore, less than half $(45 \%)$ of off-reserve First Nations children had someone who helped them to understand First Nations history and culture (Statistics Canada, 2008, Canadian Social Trends, p. 67). If these national statistics are any indication of urban Aboriginal children in Calgary, Aboriginal programs in Calgary need to offer cultural activities and they need to provide children with access to people who can help them understand their history and culture.

Urban life is difficult for Aboriginal cultures because they are not transplanted intact into a new environment (Peters, 2004, p. 11). One of the implications for public policy is the importance of support for Aboriginal cultural activities in urban areas. The Royal Commission recommended that all levels of government initiate programs to increase opportunities to promote Aboriginal cultures in urban areas (Peters, p. 11). In the 2006 Aboriginal children's survey, a survey that studies Aboriginal children's family and community lives, 
only $28 \%$ of young Métis children had participated in or attended "traditional" First Nations, Métis, or Inuit activities such as singing, drum dancing, fiddling, gatherings, or ceremonies. About one third $(31 \%)$ of Métis children had someone who helped them to understand Aboriginal history and culture (Statistics Canada, November 2008, p. 3). Ideas about the incompatibility of urban and Aboriginal cultures have a long history. Presenters to the Urban Roundtable of the Royal Commission talked about the challenges Aboriginal people face in urban areas because cities represented "an environment that is usually indifferent and often hostile to Aboriginal cultures" (Peters, 2004, p. 8).

From the Aboriginal perspective, community goes beyond the neighbourhood they live in spatially. Cultural community is extremely important, allowing urban Aboriginal people to align through their culture. In fact, "many Aboriginal people who live in urban areas retain ties with their non-urban communities of origin, and these ties represent an important component of their cultural identities" (Peters, 2005 , p. 382). Furthermore, strengthening an individual's identities and awareness of the urban Aboriginal community is one of the most effective ways to solve problems that Aboriginal people face in the city (p. 384). Finally, Peters (2005) summarizes the importance of a cultural community for Aboriginal people:

The poverty of Aboriginal peoples in Canadian cities is high, and the colonial legacy means that they face additional challenges to building community in urban areas. While there is a paucity of research on urban Aboriginal people's sense of community in urban areas, the materials that are available suggest that, while urban Aboriginal people on reserves feel more of a sense of belonging to their community, Aboriginal people in cities feel as much as a sense of belonging to their group in the city as ethnic residents do. Moreover, there is a culture of mutual assistance through shared accommodation that appears to persist in contemporary urban Aboriginal households (p. 391).

Cultural communities allow for Aboriginal people to feel more accepted and included in society, rather than isolated. They gain a sense of belonging. Even if Aboriginal people live in neighbourhoods where there are few or no other Aboriginal people, they are willing to travel to different organisations or community areas where they can interact and communicate with other Aboriginal people (e.g. Sacred Heart). Therefore, urban Aboriginal programs are important because they allow urban Aboriginals to form a cultural community and align with one another. Furthermore, these communities prevent social exclusion.

When looking at the need for urban Aboriginal programs, one must look at the history of Aboriginal peoples in Canada:

Historic inequalities have left First
Nations children, youth, and families
without much-needed supports and
services. Aboriginal people in Canada
were deprived of their land, their
cultural traditions, and their unique
way of life. Children were removed
from their families and sent away to
residential schools-where many
were abused-with well-documented
inter-generational effects. Societal
prejudices and discrimination against
Aboriginals have created additional
challenges. (Canadian Council on
Social Development [CCSD], n.d., p. 1)

In fact, "[t]he rapid change associated with urban living and loss of traditional supports have compounded feelings of isolation and dislocation among Aboriginal people, further disadvantaging their families and communities, and placing them at increased risk for involvement in the criminal justice system" (CCSD, n.d., p. 1).

Social exclusion means a lack of belonging, acceptance, and recognition. People who are socially excluded are more economically and socially vulnerable, and hence they tend to have diminished life experiences. The 2001 census data showed that certain groups were at 
particularly high risk of being socially excludedin particular, new immigrants, young workers, and Aboriginal people (CCSD, n.d., p. 1). Social exclusion and deprivation consistently emerge as underlying factors in the over-representation of Aboriginal people in the criminal justice system. For example, incarceration rates of Aboriginal people are five to six times higher than the national average. Statistics from Correctional Service Canada show that while Aboriginal people represent only $2.8 \%$ of the Canadian population, they account for $18 \%$ of those who are incarcerated in federal institutions. In the Prairie Provinces, $50 \%$ of prisoners are Aboriginal people (CCSD, n.d., p. 1).

All the above statistical and narrative information clearly articulates the need for meaningful urban programs that strengthen Aboriginal cultural traditions.

The next section discusses urban Aboriginal programs and the importance of offering programs and initiatives that embrace Aboriginal culture and traditions.

\section{Urban Aboriginal Programs}

Urban Aboriginal programs need to focus on building and protecting Aboriginal cultural communities because cultural traditions are a large part of Aboriginal people's lives. In regard to Aboriginal people building culture and community in urban areas, David Chartrand, President of the National Association of Friendship Centres, states:
Aboriginal culture in the cities is threatened in much the same way as Canadian culture is threatened by American culture, and it therefore requires a similar commitment to its protection. Our culture is at the heart of our people, and without awareness of Aboriginal history, traditions and ceremonies, we are not whole people, and our communities lose their strength... Cultural education also works against the alienation that the cities hold for our people. Social activities bring us

together and strengthen the relationship between people in areas where those relationships are an important safety net for people who feel left out by mainstream. (Cited in Peters, 2004, p. 9)

Chartrand's words exemplify the need for urban Aboriginal programs like Métis Calgary Family Services (MCFS), Native Network, and Little Dancing Buffalo. MCFS was originally established in 1992. They are "a registered, Non-profit, Charitable Aboriginal organization that practices a culturally appropriate approach to service delivery for Aboriginal families and communities (Métis Calgary Family Services Society [MCFS], 2008). Their vision is the healthy development of Native children and families and their mission is to "provide a balanced wholistic spectrum of services to Aboriginal Children and Families" (MCFS, 2008). MCFS offers a variety of programs for urban Aboriginals like Positive Indian Parenting Workshops, Crazy By Design Workshop (a two part workshop about understanding adolescents), Pow-wow Lessons, Cultural Crafts, Métis Dancing, Collective Kitchen, Grocery Bingo, and Aboriginal Students Program (ASP) Tutoring. These programs create more opportunities for Aboriginal people and they create an awareness of Aboriginal culture, history, and traditions. Furthermore, there are social and cultural activities within these programs that will help build culture and cultural community in urban areas.

According to a 2001 survey, children who participate in organized extra-curricular activities (sports, art, music, clubs, etc.) are more likely to possess greater self-esteem, to enjoy better social interactions with their friends, and to achieve relatively higher scholastic results (Statistics Canada, 2004, p. 11). Furthermore, the 2001 survey found significant differences in school performance between Aboriginal children in non-reserve areas who engaged frequently in extra-curricular activities, compared with those who rarely or never did so. Some of the most popular activities among Aboriginal children between ages 6 and 14 were time spent with Elders (34\%), art and music (31\%), and clubs or youth, drum, and dance groups (30\%) (Statistics Canada, 2004, p. 15). 


\section{Calgary's FCSS Famework, and Urban Aboriginal People}

The Aboriginal language and oral tradition components of the Native Network and Little Dancing Buffalo programs support the fact that language is often considered both an instrument and an essential part of culture. In many Aboriginal societies, "the fundamental teachings are preserved in sacred stories, ceremonies and symbols," which are "the symbols of the ideas, concepts, and beliefs of a society which has an oral tradition" (Statistics Canada, 2004, p. 17). The Royal Commission on Aboriginal Peoples (RCAP) identified several factors contributing to the decline of Aboriginal languages in Canada. Just like other minority languages in the world, Aboriginal languages are constantly being "eclipsed" or overwhelmed by more dominant languages (RCAP, 1996, p. 609). In Canada, historical factors such as residential schools have also ruptured the transmission of Aboriginal languages from one generation to the next (RCAP, p. 603).

The intent of both the Little Dancing Buffalo and Native Network programs is to increase social inclusion for a vulnerable population, since "people who are socially isolated.... are at high risk of health problems, poverty, and social exclusion" (Family and Community Support Services [FCSS], 2009b, p. 1). As FCSS (2009b) notes, "engaging vulnerable families in their communities... helps to build positive social ties" (p. 7). The programs demonstrate positive social ties, since "the research emphasizes the need for 'positive' social ties, not simply social ties in general" (FCSS, 2009b, p. 7).

Because the groups targeted by the programs are low income, they are good candidates for social inclusion interventions. After all, "[l]ow income families tend to be socially isolated, and reduced social support restricts the ability of family and community to buffer the direct effects of poverty" (FCSS, 2009b, p. 5). The benefits of increasing social support and social ties is well documented in the literature:

Extensive research reveals that social support networks can act as a significant buffer to the debilitating effects of poverty.... Scores of studies have investigated the ways in which socially isolated families can benefit from positive social ties and strengthened social support systems, and a great deal of research documents the benefits of both informal and community supports.... All parents (and all individuals) benefit from positive social support systems but, for low-income, isolated families, high-quality support systems can dramatically improve positive parenting skills, family functioning, and child outcomes. (FCSS, 2009b, p. 6)

Studies also suggest that increasing social support has a positive effect on parenting practices:

Many studies have shown that strong parenting skills and positive relationships between parents and children require both secure attachment and sufficient positive social support.... Studies indicate that social support may also influence attachment style, where parents who feel more supported tend to feel less anxious or ambivalent about their relationships with their children and become more attached to and engage in better parenting with their children. This is consistent with earlier research showing that the links between social support and better parenting include increased parental self-confidence. (FCSS, 2009b, p. 6)

The cultural elements of both programs is highly beneficial, since Pinnow (2009) states that a key principle is to "build a solid foundation in Aboriginal culture, language and spirituality through community development process" ( $p$. 2 ). Both programs provide opportunities for the use of oral traditions and mentoring in a way that is consistent with Pinnow's recommendations. She advocates the use of "oral traditions, including storytelling - for many purposes, within program contexts" because it "produces many benefits and can even be combined with modern approaches if desired" (p. 2). 
As FCSS (2009b) notes, "engaging vulnerable families in their communities... helps to build positive social ties" (p. 7). The MCFS, Little Dancing Buffalo, and Native Network programs explicitly demonstrate positive social ties; culture is a common ground among members, as opposed to bringing out divisive elements or areas of controversy. In fact, "the research emphasizes the need for 'positive' social ties, not simply social ties in general" (FCSS, 2009b, p. 7). Krech, for example, notes that celebratory activities (e.g. drumming, singing, powwow, potlatch, etc.) can revitalize the spirit and bring divided communities together (cited in Pinnow, 2009, p. 13).

The Little Dancing Buffalo program, which is offered by MCFS, is the focus of the next section.

\section{Little Dancing Buffalo}

The Little Dancing Buffalo program "provides aboriginal and Métis children and youth with instruction in traditional dance and in the culture and ceremonial significance of traditional dance both for the communities for which it is performed and for the performers who produce it" (MCFS, 2010, p. 25). In this program, Aboriginal participants are given the opportunity to learn from Aboriginal adults and Elders through various activities and cultural teachings. It offers group mentoring, cultural traditions and activities, oral traditions and teachings, and networking. So far, the program has served 171 people (98\% are Aboriginal and there were 120 females). The majority of participants were between the ages of 7 and 12 (76\%) (p. 25).

The program gives Aboriginal children a chance to develop positive social ties with peers and with other adults. These ties have been found to be important for the development of children and youth: "Extensive research documents the importance of positive social ties to the developmental outcomes of children and youth. In short, positive ties are protective factors and negative ties are risk factors for healthy development. The most important ties are with parents, peer, and other adults in the young person's life" (FCSS, 2009b, p. 9).
Since a lack of a sense of belonging and a lack of interpersonal and social skills are linked with vulnerability (FCSS, 2009b, p. 9), addressing these deficits may serve to reduce vulnerability. Furthermore, the Little Dancing Buffalo program gives children the opportunity to make new friends with other children in the same program. This connection is important because "[h]aving close friends is connected to positive emotional health and social adjustment. 'Playing together,' 'hanging out,' and 'doing things together' are among the most important features of youth friendship" (FCSS, 2009b, p. 10). Friendships have positive effects:

Youth with close friends demonstrate
better academic performance, lower
rates of criminal involvement, and lower
school drop-out rates as compared
to those who do not have friends as
sources of intimacy and social support.
Young people who are not socially
well-integrated or who have negative
peer influences report that they are
less satisfied with their lives, less
happy with their home lives, less likely
to enjoy school and to feel that they
belong at school, and more likely to
feel lonely and left out. (FCSS, 2009b,
p. 10)

Moreover, "youth development programs... help isolated children and youth to improve their social skills, make friends, and make connections with caring adult positive role models and mentors" (p. 11). Since the Little Dancing Buffalo program incorporates Aboriginal dance, cultural teachings, the Elders' oral tradition and teachings, Aboriginal ceremony, and Aboriginal language, the cultural elements of the program, both on a literal and symbolic level, stand to reverse some of the cultural losses Aboriginal people have experienced.

The following section goes into detail about the Native Network, another one of MCFS' programs.

\section{Native Network}

The Native Network program "works to connect with members of Calgary's urban Aboriginal 
population in need of services and support but who are cut off from... access to such services by virtue of their marginalization, isolation... [and/or] living circumstances" (MCFS, 2010, p. 31). Through the program, Aboriginal families and individuals gain awareness of and access to available services and supports; establish a sense of community with the Native Network Centre; and are able to participate in cultural activities and traditions. Furthermore, parents learn more about and gain confidence in their role as parents. There have been 1,843 people served in the program and $85 \%$ of them are Aboriginal. The majority of the participants were aged 26-35 (432). The program has 287 volunteers with 3,950 volunteer hours. Sixty percent of clients were female (p. 31).

Parental isolation has been identified as a risk factor for family instability and poor parenting (FCSS, 2009a, p. 3). "Socially isolated parents are more likely to use poor parenting practices.... isolated parents, without supportive networks of relatives and friends, are more likely to maltreat and neglect their children" (FCSS, 2009a, p. 5). Moreover, "many low-income families demonstrate weak communication skills with either avoidance or difficulty talking about their problems" (FCSS, 2009a, p. 4). Hence, the program could provide low-income family members with opportunities to communicate and talk about their problems.

The Native Network program also gives parents the opportunity to take part in social engagement and may also produce positive emotions, both of which have been found to have positive effects on parenting. In fact, "parents who experience frequent positive emotions and enjoy social engagement tend to be emotionally sensitive, responsive, and stimulating in their parenting" (FCSS, 2009a, p. 2).

The Native Network program also offers opportunities to enhance social networks and social support for families. It has been found that "strong and supportive interpersonal relationships... can help offset the negative consequences of low income, along with other developmental risks" (FCSS, 2009a, p. 4). Simply taking part in the program will involve individuals in their community, for, as Pinnow (2009) notes, "through the process of community members identifying their own issues, having input into program creation and implementation and even participating in the evaluation, the Aboriginal program participants become the central actors (or at least increase) in the control of the social and political environments that impact their lives" (p.1). This program also has the advantage of being family based.

\section{Little Dancing Buffalo and Native Network: Making a Difference}

Both the Little Dancing Buffalo and Native Network programs clearly address two intended areas of investment. One of these areas is in culturally-based programs to support individual development and to help re-establish linkages to families and/or Aboriginal communities. The second is community engagement and development initiatives/programs that are culturally based and appropriate. These programs also cross over into a third area of investment, which is Aboriginal mentoring and role-modeling programs to support individual development.

Both programs are culturally based and thus of high interest to the participants. Therefore, they can be compared to Lafrance's Sturgeon Lake child welfare initiative in which "he engaged the participants in a community development (perhaps community empowerment) process as a means of involving them in an issue relevant to them" (Pinnow, 2009, p. 7). Furthermore,
the research suggests that "increasing the numbers of Aboriginal community members with the skills and self- confidence to engage in community development is the first step in a process that will put everyone on a more equal footing to begin to work together" (Pinnow, p. 19).

Both the Little Dancing Buffalo and Native Network programs make extensive use of the five best/promising practices identified by Pinnow (2009), particularly the first three best/promising practices. These three practices involve 
connecting the community's men; mentoring for and by community members; and using the oral tradition. There are also opportunities to draw upon the fourth and fifth best/promising practices, which involve examining reasons for isolation and addressing them and information provision compatible with Aboriginal values.

Both programs provide ample opportunities for men to connect with their community (Pinnow's first best practices recommendation) through the traditional male roles as mentors, musicians, craftsmen, storytellers, and spiritual leaders, although women will also be involved in these roles. As Pinnow (2009, p. 12) argues:

\section{If the strength of a community is seen as inherent in the strength of its families, the well-being of men needs to be assured. Duran and Duran (1995) do an excellent job in analyzing how one of colonization's most detrimental impacts on the Aboriginal family structure has been the alienation of men from their families and their communities. Men's traditional roles of protector and provider of their families and communities were usurped by the European institutions and systems such as welfare, and their communities fragmented and destabilized by assimilative practices. It is not surprising that many Aboriginal men feel disconnected lost and dishonoured. Duran and Duran argue that the psyche of men have been especially damaged in the process of assimilation. As a result, some have taken a destruction path in their lives in which their human need for connection and nurturance has taken on destructive expression or been denied and suppressed. (Krech, 2002)}

The cultural elements of the Little Dancing Buffalo and Native Network programs are highly beneficial, since Pinnow (2009) states that a key principle is to "build a solid foundation in Aboriginal culture, language and spirituality through community development process" (p. 2 ). This principle is based on best practices developed from Krech's work on the relationship between community development and mentoring opportunities for Aboriginal men: "the process of... undertaking and sharing in specific cultural activities can bond community members and in the process, promote healing. [Krech] recommends embedding these activities into specific programs and activities that he believes have seen success" (Pinnow, p. 12).

The Native Network program has the advantage of being family based, "which generally [is] seen as more culturally appropriate by ensuring that all family members are included, particularly men (Pinnow, 20009, p. 2). Involving men in community programming centred on cultural activities and involving them in the activities for the whole family, can act as a first step toward involving them in subsequent program developments such as father support groups and other Aboriginal fatherhood projects mentioned by Pinnow (2009, p. 13). Indeed, the mentorship roles involved in the programs could be said to model positive parenting practices, giving men an "indication of the importance of the father role or [helping] them believe in their own abilities to be good fathers" and giving other program participants an "opportunity to watch a positive father role model in a positive environment" (Pinnow, p. 13).

The Little Dancing Buffalo and Native Network programs also make use of mentoring as advocated in Pinnow's second best/promising practices recommendation. Both programs are also consistent with Pinnow's conclusion that mentoring should take place "from an Aboriginal perspective, seen as more organic and incorporating more culturally based practices and approaches" (p. 2).

Both the Little Dancing Buffalo and Native Network programs create mentoring relationships between adults and children. In fact, "[n]umerous resiliency studies have demonstrated that one key factor in a youth's life is a supportive, mentoring relationship with a person who is not a parent such as a volunteer from a volunteer development program" (FCSS, 2009b, p. 11). Research demonstrates: 
that many mentoring programs are associated with a wide range of positive developmental outcomes in several areas, including (but not limited to) social skills, pro-social behaviour (helping others), and emotional wellbeing. In other words, in addition to addressing all children and youth's need for a supportive relationship with at least one supportive adult who is not a parent, mentorship programs can help young people to establish positive peer friendships. (FCSS, 2009b, p. 12).

Pinnow (2009) notes that mentoring "has long been seen as an effective approach for... positive development in youth" (p. 15), making it suitable for application in the Little Dancing Buffalo and Native Network programs. Even though "mentoring programs designed for Aboriginal youth and children are fairly rare," the Native tradition in which adults provide "friendship, guidance and support to children and youth outside of their own immediate families... was an established practice prior to European contact" (Pinnow, p. 15). It should be noted, however, that thorough evaluations of intergenerational programs have not yet been carried out (FCSS, 2009b, p. 12).

Elders will provide the mentoring in both the Little Dancing Buffalo and Native Network programs and will be working with groups (mainly of children). The mentoring that they deliver in these programs is consistent with the recommendations of researchers. Researchers recommend that mentoring present "the Indigenous worldview of education, which is more holistic rather than individualistic" and argue that group mentoring is more profitable in an informal setting that "is not only compatible with cultural traditions of learning but also will model positive relationships and interactions" (Pinnow, 2009, p. 15). The use of Aboriginal Elders as mentors is also in line with the research, which suggests that "Aboriginal mentors would be most beneficial to teach Aboriginal values and common experiences," thus providing mentoring that is in support of "community values and activities" (Pinnow, p. 16).
Elders mentoring youth is of critical significance in order to preserve the traditional culture, some of which has been lost in moving to new urban environments (Pinnow, 2009, p. 18). In fact, through this mentoring, elements of the culture are not lost with the passing of the Elders. "Children must be taught about their ancestors, their history, and their alliances through story, ceremony, and language" (Lafrance \& Bastien, 2007, p. 120).

Nevertheless, children and youth can also, within both programs, mentor each other to some extent, since peers and friends are often identified as having the most influence on the behaviour of children and youth (Pinnow, $p$. 19). As Lafrance and Bastien (2007) report, one positive outcome of the Making Our Hearts Sing initiative in Alberta was that youth "are being asked to contribute to their community and to help other youth," even though "Elders are increasingly recognized as an important source of wisdom and experience" (p. 108).

In addition, mentoring occurs within a family context in the Native Network program, which is consistent with research findings that family should be "an essential partner in any mentoring program" (Pinnow, p. 15), since the family is viewed as the primary network in Native communities. Furthermore, the "gathering" that is involved in the Native Network program can help community members to think about how they can help one another and adopt mentorship roles with others: "[Krech] believes that such gatherings help community members focus on helping each other to begin the healing journey. $\mathrm{He}$ sees the proceedings of these gatherings and activities as an opportunity for individuals of all ages to be called upon to become mentors" (Pinnow, 2009, p. 13).

Storytelling and other cultural activities drawing on the wisdom and knowledge of the Elders can be part of "helping each member feel valued for the unique gifts they had," enabling the community "to look inwards to identify and use its own resources and strengths" (Pinnow, p. 8). Reflecting on the success of storytelling activities at Sturgeon Lake, Lafrance writes: 
This phase of the journey aimed for empowerment through the sharing of stories in a safe, supportive environment that called forth the collective power and support of community members. The intent was to develop a community based 'wellness vision' through the sharing of personal stories recounting past experiences and their subsequent impact on individuals and their community... to promote healing of the community. (cited in Pinnow, 2009, p. 8)

In fact, storytelling activities were a crucial part of the highly successful appreciative inquiry approach used in the Alberta Making Our Hearts Sing (MOHS) initiative:

... storytelling is the primary data collection approach of Appreciative Inquiry, a practice that is congruent with the Aboriginal oral tradition. Storytelling has been conceptualized as a consciousness raising type of activity that allows people to relate to each other, develop greater selfawareness, break the silence, and contextualize their experiences from their own worldview (Abosolon \& Willett, 2004). In summary, the Appreciate Inquiry approach provides a holistic and participatory approach that values multiple ways of knowing and working collaboratively from a strengths perspective toward a shared vision. (Lafrance \& Bastien, 2007, pp. 114-115)

Although the Native Network program does not explicitly call for a discussion "examining reasons for isolation and addressing these" (Pinnow's fourth best/promising practice), the very experience of coming together with community members and interacting with them as part of the program will no doubt spur reflection and lead participants to think about their current and future level of community involvement. After all, the Native Network program includes a gathering as well as the components of family inclusiveness, community engagement, socializing, role modelling, and storytelling, all of which may allow possibilities for participants to air their thoughts on the empowerment of community involvement versus the powerlessness of isolation. "Gatherings revitalize traditional ways for strengthening the affinity of collective and family ties, affirming and utilizing knowledge building, decreasing external dependencies, developing indigenous leadership and practices, and creating new sources of knowledge for recovery" (Lafrance \& Bastien, 2007, p. 120).

As in Winnipeg's Spence Neighbourhood community development program, it should be possible within both the Little Dancing Buffalo and Native Network programs, to gather information from the participants (for example, through program evaluation materials) on factors influencing their degree of involvement in the community and their view of community development (Pinnow, 2009, p. 17). Furthermore, the program participants will tend to informally discuss amongst themselves their own involvement in the community and its programs. It is important to discover "what aspects of community are important to [the] Aboriginal community" (Pinnow, p. 21).

By including spiritual elements and smudging in the Native Network project, this encourages the participants to reflect on their lives and the deeper significance of their lives. Similarly, the Little Dancing Buffalo project encourages spiritual practices through incorporating spiritual elements in Aboriginal ceremonies and, to some extent, in other program components as Aboriginal dance, cultural teachings, and Elder's oral teachings. Thus, both programs are consistent with the efforts of Aboriginal people "to renew and invigorate their own spirituality as a source of strength" (Lafrance \& Bastien, 2007, p. 113).

Further, developing spirituality in youth and families can help create the desired outcome of increased social inclusion because "Aboriginal social work and traditional healing ... are founded on a spiritual sense of interconnectedness" (Lafrance \& Bastien, 2007, p. 114). Indeed, the Making Our Hearts Sing initiative identified "the importance of kinship and connection to each 
other and a respectful approach to the planet" (Lafrance \& Bastien, p. 117), both of which can be said to reflect "a consistent application of spirituality to all of life" (p. 116).

In the case of the Sturgeon Lake initiative, the spiritual vision of the future that the participants had in mind led them toward the outcome desired:

The community's vision of a safe place for children and, ultimately, a healthy community led them to initiate an important process of reflecting upon that experience to identify what contributed to and what mitigated against the achievement of their vision. The participants began with a vision of an improved and friendlier child welfare system. Their journey has led to a broader vision; one of child, family and community wellness; a vision that is informed by the stories of the people of Sturgeon Lake. As these stories were told and heard, healing began to occur and the people were increasingly empowered. As they became empowered, they were able to give more fully of themselves and to contribute to the development of health among their brothers and sisters in the community. (Lafrance, 2003, p. 119)

The information provided by the programs is compatible with Aboriginal values because it is delivered to a significant extent by Elders and through such traditional mediums as storytelling. Thus, a strong point of the programs, from the point of view of the research, is their "cultural appropriateness" and "respect for Indigenous knowledge," both of which are mentioned by Pinnow (2009, p. 20) as important factors in the provision of information. Including Aboriginal language within the Little Dancing Buffalo program is also of significance because Pinnow identifies that, in terms of knowledge exchange in Native communities, the capacity "to communicate in Aboriginal dialects is a tremendous asset" ( $p$. 20). Participants in the Making Our Hearts Sing initiative further identified "the importance of language as a source of renewed culture, [and] knowledge of history and tradition as an essential element of identity" (Lafrance \& Bastien, 2007, p. 117). Indeed, "language guides the epistemology and pedagogical practices of the Tribe; it is instrumental in creating knowledge and creating reality" (Lafrance \& Bastien, p. 119).

There is also the possibility that these programs could lead to further programs, as have occurred in other cities, in which cultural teachings are recorded or videotaped for posterity or in which stories or information gathered could be made available to the community through electronic means such as the Internet (Pinnow, 2009, p. 20). Also, both programs will provide an opportunity for social services personnel to familiarize themselves with the language and terminology used by the program participants and vice versa. In this way, those carrying out the program will, over time, gain "information on Aboriginal perspectives on the meaning and/or use of various terms" (Pinnow, 2009, p. 4), thus allowing for the necessary adjustments over time so as to help "establish information provision compatible with Aboriginal values" (Pinnow's fifth best practice recommendation). As Lafrance and Bastien (2007) state:
As we reflect upon the seemingly inexorable flow of Aboriginal children into non-Aboriginal care, it is imperative to reflect upon our professional beliefs and assumptions in the delivery of child welfare services. It seems evident that current services and programmatic paradigms exist in direct opposition to traditional Aboriginal ways of thinking.... It seems timely to reflect upon the foundations of such programs as Aboriginal people seek return to traditional worldviews and values to replace what they view as unworkable program models that only worsen their current situation. (p. 106)

Pinnow points out that some terminology used in the creation and implementation of programs "may have very different meanings from an Aboriginal perspective" (p. 5). For example, Pinnow reports that Blackstock, a child and family services expert from the Gitxsan Nation, conceptualized her work not in terms of social 
inclusion but in terms of reconciliation and social justice (p. 5). By having Elders involved in delivery of the programs, participants may thus see any social issues in their own terms and from their own perspective. For example, they may see social welfare issues as resulting from structural violence as opposed to deficiencies on their part in terms of community participation. "Many are concerned that the child welfare experience may inadvertently parallel the colonial experience of residential schools and may have similar long-term negative ramifications for Aboriginal communities" (Lafrance \& Bastien, 2007, p. 115).

Providing information in a way that is compatible with Aboriginal values and coming to a greater understanding of the Aboriginal worldview will ultimately enable child welfare providers to develop better programs that reflect Aboriginal needs:

\begin{abstract}
We are finding that to support Aboriginal self-determination in the development of policies and practices that are in keeping with Aboriginal traditions and beliefs calls for an uncommon degree of humility and a high degree of receptivity to different ways of thinking.... For those who wish to support community efforts perhaps the answer lies in finally accepting the wisdom of Aboriginal colleagues and elders as our guides in this journey. (Lafrance \& Bastien, 2007, pp. 111-112)
\end{abstract}

The Little Dancing Buffalo and Native Network programs also offer child welfare providers the opportunity to "develop a framework of analysis that provides an understanding of the history and current reality of Aboriginal people and culture," thus facilitating "Aboriginal ownership and leadership in child welfare" (Lafrance \& Bastien, 2007, p. 116).

\section{Conclusion}

Through its new social sustainability framework, FCSS is able to fund Aboriginal programs that have a preventive and comprehensive impact on the community and sustainability for FCSS. By using the framework to maximize the impact of FCSS's investments in the community, programs are able to create positive changes for Aboriginal people. These programs help Aboriginal people with their transitions to urban life, providing support, a sense of belonging, and a community that appreciates Aboriginal traditions and values. Programs like Little Dancing Buffalo and the Native Network incorporate FCSS's principles and embrace Aboriginal culture.

\section{References}

Aboriginal Relations. (2011, July 12). 2011-2012 Ministry E-Scan. Unpublished Manuscript.

Canadian Council on Social Development. (n.d.) Social challenges: The well-being of Aboriginal people. Retrieved November 10, 2009, from http://www.ccsd. ca/cpsd/ccsd/c_ab.htm.

City of Calgary. (2010, September 7). FCSS Overview. Retrieved November, 2010 from the City of Calgary: FCSS Web site: http://www.calgary.ca/fcss.

City of Calgary. (2010, September 7). Social Sustainability Framework and Funding Priorities. Retrieved November, 2010 from the City of Calgary: FCSS Web site: http://www.calgary.ca/fcss.

Cooper, Merrill and Deborah Bartlett. (2008, August 27). A New Funding Framework and Priorities for FCSS Calgary. Retrieved November, 2010 from the City of Calgary: FCSS Web site: http://www.calgary.ca/fcss.

Family and Community Support Services. (2009a, June). Outcome: Positive parenting and family functioning [FCSS Calgary Research Brief No. 2]. Calgary, AB: Author.

Family and Community Support Services. (2009b, June). Outcome: Positive social ties and vulnerable populations [FCSS Calgary Research Brief No. 4]. Calgary, AB: Author.

Family and Community Support Services (FCSS) Fact Sheet (2010). Retrieved November, 2010 from the City of Calgary: FCSS Web site: http://www.calgary.ca/fcss

Lafrance, J. (2003). The Sturgeon Lake community experience: A journey toward empowerment. Pimatziwin: A Journal of Aboriginal and Indigenous Community Health, 1(1), 115-143.

Lafrance, J., \& Bastien, B. (2007). Here be dragons! Reconciling indigenous and western knowledge to improve Aboriginal child welfare. First Peoples Child \& Family Review, 3(1), 105-126. 


\section{Calgary's FCSS Famework, and Urban Aboriginal People}

Métis Calgary Family Services Society. (2008). Retrieved December, 2010 from Métis Calgary Family Services Society Website: http://www.mcfs.ca/index.htm.

Métis Calgary Family Services Society. (2010). 20092010 Overview of Programs and Services Provided to Calgary's Urban Aboriginal/Métis Communities. Unpublished Manuscript.

Peters, E. (2004, March 25). Three myths about Aboriginals in cities [Breakfast on the Hill Seminar Series]. Retrieved from www.fedcan.ca/images/File/PDF/BOH/ breakfast-peters0304.pdf.

Peters, Evelyn. (2005). Indigeneity and marginalisation: Planning for and with urban Aboriginal communities in Canada. Progress in Planning, 63, 327-404.

Pinnow, J. (2009, September). Aboriginal people helping Aboriginal people: Best practices in preventative Aboriginal programming seen through the lens of decreasing social exclusion and increasing social ties [Draft prepared for Family and Community Support Services]. Calgary, AB: Family and Community Support Services.

Statistics Canada. (2004, July 9). A portrait of Aboriginal children living in non-reserve areas: Results from the 2001 Aboriginal Peoples Survey. Retrieved November 9 , 2009, from http://www.statcan.gc.ca/pub/89597-x/2001001/index-eng.htm. 